\title{
A novel damage mechanism: Contribution of the interaction between necroptosis and ROS to high glucose-induced injury and inflammation in $\mathrm{H} 9 \mathrm{c} 2$ cardiac cells
}

\author{
WEIJIE LIANG ${ }^{1,2}$, MEIJI CHEN ${ }^{3}$, DONGDAN ZHENG $^{4}$, JIEYI HE $^{1,2}$, MINGCAI SONG $^{1,2}$, \\ LIQIU MO ${ }^{5}$, JIANQIANG FENG ${ }^{6,7}$ and JUN LAN ${ }^{6,7}$
}

${ }^{1}$ Department of Cardiology, Central Hospital of Panyu District; ${ }^{2}$ Cardiovascular Institute of Panyu District, Guangzhou, Guangdong 511400; Departments of ${ }^{3}$ Pediatrics, ${ }^{4}$ Cardiac Care Unit and ${ }^{5}$ Anesthesiology, Huangpu Division of The First Affiliated Hospital of Sun Yat-sen University, Guangzhou, Guangdong 510700; ${ }^{6}$ Department of Cardiology, The Third People's Hospital of Dongguan; ${ }^{7}$ Cardiovascular Institute of Dongguan, Dongguan, Guangdong 523326, P.R. China

Received March 26, 2016; Accepted May 15, 2017

DOI: 10.3892/ijmm.2017.3006

\begin{abstract}
Recently, a novel mechanism known as 'programmed necrosis' or necroptosis has been shown to be another important mechanism of cell death in the heart. In this study, we investigated the role of necroptosis in high glucose (HG)-induced injury and inflammation, as well as the underlying mechanisms. In particular, we focused on the interaction between necroptosis and reactive oxygen species (ROS) in H9c2 cardiac cells. Our results demonstrated that the exposure of $\mathrm{H} 9 \mathrm{c} 2$ cardiac cells to $35 \mathrm{mM}$ glucose ( $\mathrm{HG}$ ) markedly enhanced the expression level of receptor-interacting protein 3 (RIP3), a kinase which promotes necroptosis. Importantly, co-treatment of the cells with $100 \mu \mathrm{M}$ necrostatin-1 (a specific inhibitor of necroptosis) and $\mathrm{HG}$ for $24 \mathrm{~h}$ attenuated not only the increased expression level of RIP3, but also the HG-induced injury and inflammation, as evidenced by an increase in cell viability, a decrease in ROS generation, the attenuation of the dissipation of mitochondrial membrane potential and a decrese in the secretion levels of inflammatory cytokines, i.e., interleukin (IL)-1 $\beta$ and tumor necrosis factor (TNF)- $\alpha$. Furthermore, treatment of the cells with $1 \mathrm{mM}$ N-acetyl-L-cysteine (a scavenger of ROS) for $60 \mathrm{~min}$ prior to exposure to HG significantly reduced the HG-induced increase in the RIP3 expression level, as well as
\end{abstract}

Correspondence to: Dr Liqiu Mo, Department of Anesthesiology, Huangpu Division of The First Affiliated Hospital of Sun Yat-sen University, 183 Huangpu Dong Road, Guangzhou, Guangdong 510070, P.R. China

E-mail: mlqiu11220@126.com

Dr Jun Lan, Department of Cardiology, The Third People's Hospital of Dongguan, 1 Xianglong Road, Shilong Town, Dongguan, Guangdong 523326, P.R. China

E-mail: dgsdsrmyylj@126.com

Key words: necroptosis, reactive oxygen species, interaction, injury, inflammation, high glucose, H9c2 cells the injury and inflammatory response described above. Taken together, the findings of this study clearly demonstrate a novel damage mechanism involving the positive interaction between necroptosis and ROS attributing to HG-induced injury and inflammation in H9c2 cardiac cells.

\section{Introduction}

Accumulating evidence indicates that hyperglycemia is recognized as the most important factor inducing almost all cardiovascular complications associated with chronic diabetes, such as diabetic cardiomyopathy (DCM) (1-4). Multiple factors have been demonstrated to participate in hyperglycemiainduced cardiac injury, such as reactive oxygen species (ROS) generation (3-5), apoptosis (3,6-8) and the activity of several signaling molecules, including mitogen-activated protein kinase (MAPK) $(3,4,6,9)$, p53 $(7,10)$ and nuclear factor- $\kappa \mathrm{B}(\mathrm{NF}-\kappa \mathrm{B})(11,12)$. In addition, inflammation is also involved in high glucose (HG)-induced cardiomyocyte injury (13). More recently, we indicated that the NF- $\kappa \mathrm{B}$ and interleukin-1 $\beta$ (IL-1 $\beta$ ) pathways are implicated in the HG-elicited injury and inflammation in H9c2 cardiac cells (13). However, the mechanisms responsible for the deteriorative effects of hyperglycemia on cardiomyocytes are complex, and are not yet fully understood. Thus, to explore the detailed mechanisms underlying hyperglycemia-induced cardiomyocyte injury is important for the prevention and treatment of diabetic cardiovascular complications.

Recently, a novel mechanism known as 'programmed necrosis' or necroptosis has been considered as another important mediator of cell death in the heart (14). Similar to apoptosis, necroptosis is tightly regulated by distinct molecules, but leads to the typical morphological characteristics of necrosis, such as defects in membrane integrity and inflammation, thus combining the features of both mechanisms (14-16). In vitro studies have indicated that the tumor necrosis factor- $\alpha$ (TNF- $\alpha$ )-dependent formation of a complex between receptor-interacting protein (RIP) 1 and another kinase, RIP3 is an essential step for inducing necroptosis $(15,17,18)$. In this 
process, RIP3 appears to play an important role, controlling RIP1 phosphorylation, a necessary step in necroptosis $(15,18)$.

Increasing evidence has demonstrated that necroptosis is involved in a number of pathological processes in cardiovascular diseases (19-27). In hearts affected by ischemia/ reperfusion (I/R), RIP1 and RIP3 expression and phosphorylation have been shown to be increased, and the necroptosis inhibitor, necrostatin-1 (Nec-1) reduces the infarct size (23-25). RIP3 expression has also been shown to be enhanced in hearts affected by ischemia and RIP3 deficiency protects mouse heart function (26). In addition, Luedde et al revealed that RIP3 mediates the inflammatory response in mice with myocardial infarction (26). Collectively, the above-mentioned studies suggest that necroptosis is implicated in ischemic cardiac lesions (23-26) and inflammation (27). However, the exact role of necroptosis in diabetic cardiac injury and inflammation remains unclear.

ROS are highly reactive molecules that have been considered to function both as second messengers of TNF- $\alpha$-elicited cell death and modulators of signaling pathways $(28,29)$. Since both ROS and necroptosis have been reported to be involved in cell death and inflammation, the interaction between ROS and necroptosis has recently attracted attention. Classically, the execution of necroptosis is believed to involve the generation of ROS and mitochondrial dysfunction $(30,31)$. On the other hand, RIP3 has been demonstrated to be a key regulator in energy metabolism-associated ROS generation, which partially accounts for the ability of RIP3 to promote necrosis $(16,32)$. In addition, RIP3 has been repeatedly reported to regulate ROS production $(18,26,33)$. Of note, a more recent study demonstrated that in BV6/TNF- $\alpha$-treated Jurkat cells, there was a positive interaction between necroptosis and ROS, as on the one hand, radical scavengers reduced necroptosis, but on the other hand, ROS generation was decreased by the knockdown of RIP1 or RIP3 (34). Since both necroptosis and ROS play critical roles in cell death in the heart (14), it would of interest to explore whether there is a positive interaction between necroptosis and ROS in hyperglycemia-induced cardiac injury and inflammation in order to provide a novel mechanistic explanation for diabetic cardiac lesions.

In this study, we report that HG induces necroptosis-dependent cardiac injury and inflammation. Furthermore, there was a positive interaction between necroptosis and ROS generation, which plays important roles in HG-induced injury and inflammation in $\mathrm{H} 9 \mathrm{c} 2$ cardiac cells.

\section{Materials and methods}

Materials. Anti-RIP3 antibody (cat. no. ab152130) was purchased from Abcam (Cambridge, MA, USA); anti-GAPDH antibody (cat. no. 10494-1-AP) was purchased from Proteintech Group, Inc. (Wuhan, China). Dulbecco's modified Eagle's medium (DMEM) medium and fetal bovine serum (FBS) were purchased from Gibco-BRL (Grand Island, NY, USA). The BCA protein quantification kit and horseradish peroxidase (HRP)-conjugated goat anti-rabbit secondary antibody were obtained from KangChen Bio-tech (Shanghai, China). N-acetyl-L-cysteine (NAC), rhodamine 123 (Rh123), Nec-1 and 2',7'-dichlorofluorescein diacetate (DCFH-DA) were obtained from Sigma-Aldrich (St. Louis, MO, USA).
Enhanced chemiluminescence (ECL) solution was purchased from KeyGen Biotech Co., Ltd. (Nanjing, China). The Cell Counting Kit-8 (CCK-8) was offered by Dojindo Laboratories (Kumamoto, Japan). IL-1 $\beta$ and TNF- $\alpha$ enzyme-linked immunosorbent assay (ELISA) kits were purchased from Cusabio Biotech Co., Ltd. (Wuhan, China). The H9c2 cardiac cells were supplied by the Sun Yat-sen University Experimental Animal Center (Guangzhou, China).

Cell culture and treatments. H9c2 cardiac cells, derived from rat embryonic ventricular cardiomyocytes, were maintained in DMEM, supplemented with $10 \%$ FBS in a humidified incubator with $95 \%$ air and $5 \% \mathrm{CO}_{2}$ at $37^{\circ} \mathrm{C}$. The culture medium was replaced with fresh medium every 2-3 days. When the cells grew to approximately $80 \%$ confluency, they were expanded to new culture plates.

In the control group, $\mathrm{H} 9 \mathrm{c} 2$ cardiac cells were incubated with $5.5 \mathrm{mM}$ glucose. To observe the effects of glucose at $35 \mathrm{mM}$ glucose (HG) on the expression level of RIP3, the cells were exposed to $\mathrm{HG}$ for 3, 6, 9, 12 and $24 \mathrm{~h}$ (Fig. 1). In order to examine the effect of necroptosis on HG-induced injury, the H9c2 cells were co-processed with different concentrations $(75,100,200,400,600$ and $800 \mu \mathrm{M}$ ) of Nec-1 (a specific inhibitor of necroptosis) and $\mathrm{HG}$ for $24 \mathrm{~h}$. To determine whether there was an interaction between necroptosis and ROS, the $\mathrm{H} 9 \mathrm{c} 2$ cells were treated with $1 \mathrm{mM}$ NAC (a scavenger of ROS) for $60 \mathrm{~min}$ prior to $\mathrm{HG}$ exposure.

Western blot analysis. After being subjected to the indicated treatments, the H9c2 cardiac cells were harvested and lysed with RIPA buffer containing $1 \mathrm{mM}$ phenylmethanesulfonyl fluoride (PMSF) at $4^{\circ} \mathrm{C}$ for $30 \mathrm{~min}$. The protein concentration was determined using the BCA protein quantification kit. Loading buffer was added to the cytosolic extracts and after boiling for approximately $5 \mathrm{~min}$, equal amounts of supernatant from each sample were subjected to $10 \%$ sodium dodecyl sulphate-polyacrylamide gel electrophoresis (SDS-PAGE). The separated proteins were transferred onto polyvinylidene difluoride (PVDF) membranes followed by the blocking of the membranes with fresh blocking buffer [0.1\% Tween-20 in Tris-buffered saline (TBS-T) containing 5\% fat-free milk] for approximately $90 \mathrm{~min}$ at room temperature. The membranes were then incubated with either anti-RIP3 or anti-GAPDH (1:1,000 dilution) antibody in freshly prepared TBS-T with $3 \%$ fat-free milk overnight with slow agitation at $4^{\circ} \mathrm{C}$ temperature. Following 3 washes with TBS-T, the membranes were incubated with HRP-conjugated goat anti-rabbit secondary antibody (1:2,500 dilution) in TBS-T with $3 \%$ fat-free milk for $90 \mathrm{~min}$ at room temperature. The membranes were then washed 3 times with TBS-T solution for $15 \mathrm{~min}$. The immunoreactive signals were visualized by using ECL detection. In order to quantify the protein expression, the $\mathrm{X}$-ray films were scanned and analyzed using ImageJ $1.47 \mathrm{i}$ software. The experiment was repeated 5 times.

Cell viability assay. CCK-8 assay was applied to detect the viability of the cells. The H9c2 cells were digested and seeded in a 96-well growth-medium plate at a concentration of $1 \times 10^{4}$ cells $/ \mathrm{ml}$ and incubated at $37^{\circ} \mathrm{C}$. After the indicated treatments, the cells were washed twice with phosphate-buffered 
saline (PBS). Subsequently, $10 \mu \mathrm{lCCK}-8$ test solution and $90 \mu \mathrm{l}$ DMEM were added to each well, and the cells were incubated at $37^{\circ} \mathrm{C}$ for $2.5 \mathrm{~h}$. The absorbance value (OD value) at the $450 \mathrm{~nm}$ wavelength was measured using a microplate reader (Molecular Devices, Sunnyvale, CA, USA). The means of the optical density (OD) of 3 wells in the indicated groups were used to calculate the percentage of cellular activity according to the following formula: cell viability $(\%)=\left(\mathrm{OD}_{\text {treatment group }} / \mathrm{OD}_{\text {control }}\right.$ group) $\mathrm{x} 100 \%$. The experiment was repeated 5 times.

Measurement of the secretion levels of $I L-1 \beta$ and TNF- $\alpha$ by ELISA. The H9c2 cells were seeded in 96-well growth-medium plates. After the indicated treatments, the levels of IL- $1 \beta$ and TNF- $\alpha$ in the culture supernatant were evaluated by ELISA according to the manufacturer's instructions (Cusabio Biotech Co., Ltd.). The experiment was performed 5 times.

Measurement of the intracellular ROS level. The intracellular level of ROS was detected using the redox-sensitive fluorescent dye, DCFH-DA. Briefly, the culture medium was removed and the cells were washed 3 times with PBS. The cells were incubated with DCFH-DA $(10 \mu \mathrm{M})$ which was diluted by serum-free medium at $37^{\circ} \mathrm{C}$ during the last $20 \mathrm{~min}$. The cells were then washed 5 times with PBS and the relative amount of fluorescent product was captured using a fluorescence microscope connected to an imaging system (BX50-FLA; Olympus, Tokyo, Japan). ImageJ $1.47 \mathrm{i}$ software was applied to analyze the mean fluorescence intensity (MFI) of DCFH-DA, which indirectly showed the level of cell ROS. The experiment was carried out 5 times.

Measurement of mitochondrial membrane potential (MMP). MMP was assessed using a fluorescent dye, Rh123, an indicator of mitochondrial polarization that preferentially enters the mitochondria based on the highly negative MMP. The depolarization of MMP leads to the loss of Rh123 from the mitochondria and a decrease in intracellular green fluorescence. The H9c2 cardiac cells were plated in 24-well plates. After the indicated treatments, the cells were washed 3 times with PBS. The $\mathrm{H} 9 \mathrm{c} 2$ cells were incubated with $1 \mu \mathrm{M} \mathrm{Rh} 123$ at $37^{\circ} \mathrm{C}$ for $30 \mathrm{~min}$ in an incubator and washed 3 times with PBS. The Rh123 fluorescence was then measured over the entire field of vision using a fluorescence microscope connected to an imaging system (BX50-FLA; Olympus). The MFI of Rh123 from 5 random fields was analyzed using ImageJ 1.47i software and was regard as an index of the level of MMP. The experiment was carried out 5 times.

Statistical analysis. All data are expressed as the means \pm SEM. Differences between groups were determined by one-way analysis of variance (ANOVA) using SPSS 13.0 software (SPSS, Inc., Chicago, IL, USA) followed by the least significant difference (LSD) post hoc comparison test. Differences were considered statistically significant at a P-value $<0.05$.

\section{Results}

Inhibitor of necroptosis attenuates the HG-induced upregulation of RIP3 expression in H9c2 cardiac cells. Based on the results from our primary dose-response experiment (data
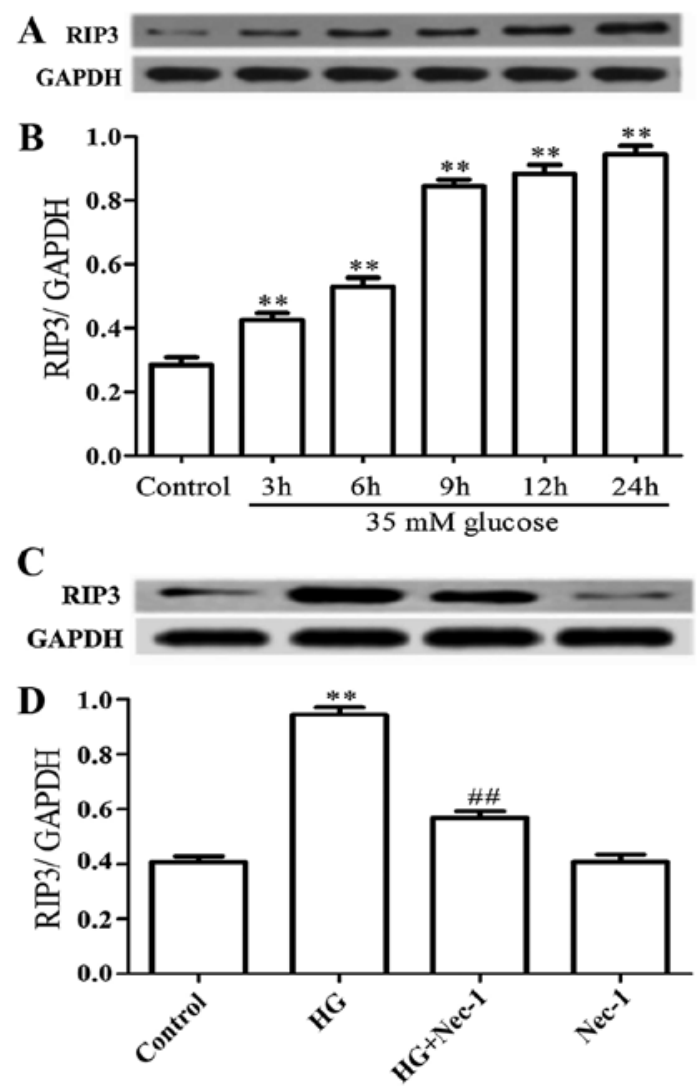

Figure 1. Inhibitor of necroptosis attenuates the high glucose (HG)-induced increase in the expression level of receptor-interacting protein 3 (RIP3) in H9c2 cardiac cells. The expression level of RIP3 was semi-quantified by western blot analysis. (A) H9c2 cardiac cells were exposed to $35 \mathrm{mM}$ glucose (HG) over a 24-h time period. (C) H9c2 cardiac cells were exposed to HG in the absence or presence of co-treatment with $100 \mu \mathrm{M}$ necrostatin-1 (Nec-1) for $24 \mathrm{~h}$. (B and D) Densitometric analysis of the RIP3 expression levels in (A) and $(C)$. Data are shown as the means $\pm \operatorname{SEM}(n=5) .{ }^{* *} \mathrm{P}<0.01$ vs. control group (the cells were incubated with $5.5 \mathrm{mM}$ glucose for $24 \mathrm{~h}$ ); ${ }^{\# \#} \mathrm{P}<0.01 \mathrm{vs}$. the HG-exposed group.

not shown), $35 \mathrm{mM}$ glucose was selected as an effective injury-inducing concentration for $\mathrm{H} 9 \mathrm{c} 2$ cardiac cells in our recent studies $(3,13)$. In this study, to examine the effect of HG (35 mM glucose) on the protein expression of RIP3 in $\mathrm{H} 9 \mathrm{c} 2$ cardiac cells, a time-response experiment to evaluate the protein expression level of RIP3 was performed. As shown in Fig. 1A and B, after the cells were exposed to $\mathrm{HG}$ for 3, 6, 9, 12 and $24 \mathrm{~h}$, the protein expression level of RIP3 was markedly increased $(\mathrm{P}<0.01)$, reaching the maximum level at $24 \mathrm{~h}$.

Of note, co-treatment of the H9c2 cardiac cells with $100 \mu \mathrm{M} \mathrm{Nec}-1$ (a specific inhibitor of necroptosis) and HG for $24 \mathrm{~h}$ considerably blocked the upregulation of RIP3 expression induced by HG (Fig. 1C and D; P<0.01). Alone $100 \mu \mathrm{M} \mathrm{Nec-1}$ did not alter the basal expression level of RIP3.

Scavenger of ROS ameliorates the HG-induced upregulation of RIP3 expression in $\mathrm{H} 9 \mathrm{c} 2$ cardiac cells. Since Schenk et al (34) have indicated that ROS is involved in the regulation of BV6/ TNF- $\alpha$-induced necroptosis in Jurkat cells, in this study, we evaluated the role of ROS in the HG-induced upregulation of RIP3 expression in H9c2 cardiac cells. As shown in Fig. 2, treatment of the cells with $1 \mathrm{mM}$ NAC (a scavenger of ROS) for $60 \mathrm{~min}$ prior to exposure to $\mathrm{HG}$ for $24 \mathrm{~h}$ markedly inhibited the 
increased protein expression level of RIP3. NAC at $1 \mathrm{mM}$ alone did not affect the basal expression level of RIP3 in H9c2 cardiac cells. The above-mentioned results indicate that ROS participates in the HG-induced upregulation of RIP3 expression.

Necroptosis is involved in $H G$-induced oxidative stress in H9c2 cardiac cells. As shown in Fig. 3A-b and B, exposure of the cells to $35 \mathrm{mM}$ glucose ( $\mathrm{HG}$ ) for $24 \mathrm{~h}$ significantly increased the intracellular generation of ROS. However, co-treatment of the cells with $100 \mu \mathrm{M} \mathrm{Nec-1}$ and HG for $24 \mathrm{~h}$ markedly attenuated the increased generation of ROS (Fig. 3A, panel $\mathrm{c}$ and B). Alone $100 \mu \mathrm{M} \mathrm{Nec}-1$ did not affect the basal intracellular generation of ROS. These results indicated that necroptosis contributes to the HG-induced overproduction of ROS in cardiac cells.

Necroptosis and ROS are implicated in HG-induced cytotoxicity to H9c2 cardiac cells. Consistent with previous studies $(3,9,13)$, the exposure of H9c2 cardiac cells to HG for $24 \mathrm{~h}$ markedly induced cytotoxicity, leading to a decrease in cell viability. Co-treatment of the cells with $\mathrm{HG}$ and 75 , $100,200,400,600,800 \mu \mathrm{M}$ of Nec-1 for $24 \mathrm{~h}$ considerably reduced HG-induced cytotoxicity, as evidence by an increase in cell viability (Fig. 4A), and at the concentration of $100 \mu \mathrm{M}, \mathrm{Nec}-1$ exhibited the most prominent anti-cytotoxic effect. Thus, $100 \mu \mathrm{M}$ was used as the effective concentration of Nec-1 in the following experiments. Alone, Nec-1 at 75, $100,200,400,600$ and $800 \mu \mathrm{M}$ did not significantly affect cell viability (Fig. 4B). Similar to the protective effects of Nec-1 against HG-induced cytotoxicity, pre-treatment of the $\mathrm{H} 9 \mathrm{c} 2$ cardiac cells with $1 \mathrm{mM}$ NAC also antagonized the HG-induced cytotoxicity, leading to an increase in cell viability (Fig. 4C). Alone, $1 \mathrm{mM}$ NAC did not significantly alter cell viability. The above-mentioned data suggest that necroptosis and ROS mediate cytotoxicity in HG-exposed H9c2 cardiac cells.

Necroptosis and ROS are linked to HG-induced mitochondrial insults in H9c2 cardiac cells. Exposure of the cells to HG for $24 \mathrm{~h}$ markedly induced mitochondrial damage, leading to a loss of MMP (Fig. 5A, panel b and B). However, co-treatment of the cells with $100 \mu \mathrm{M} \mathrm{Nec}-1$ and $\mathrm{HG}$ for $24 \mathrm{~h}$ or treatment of the cells with $1 \mathrm{mM} \mathrm{NAC}$ for $60 \mathrm{~min}$ prior to exposure to HG for $24 \mathrm{~h}$ markedly attenuated the HG-induced dissipation of MMP (Fig. 5A, panels c and d, and B). Alone, $100 \mu \mathrm{M} \mathrm{Nec-1}$ and $1 \mathrm{mM}$ NAC did not significantly affect the MMP of the cells. These results indicate that necroptosis and ROS are involved in HG-induced mitochondrial damage.

Necroptosis and ROS mediate the HG-induced secretion of pro-inflammatory cytokines in $\mathrm{H} 9 \mathrm{c} 2$ cardiac cells. As shown in Fig. 6, after the cells were treated with HG for $24 \mathrm{~h}$, the secretion levels of IL-1 $\beta$ (Fig. 6A) and TNF- $\alpha$ (Fig. 6B) were markedly increased, as compared with the control group $(\mathrm{P}<0.01)$. However, co-treatment of the cells with $100 \mu \mathrm{M} \mathrm{Nec-1}$ and HG for $24 \mathrm{~h}$ or treatment of the cells with $1 \mathrm{mM}$ NAC for $60 \mathrm{~min}$ prior to exposure to $\mathrm{HG}$ for $24 \mathrm{~h}$ markedly alleviated the increased production of IL- $1 \beta$ and TNF- $\alpha$, revealing that necroptosis and ROS contribute to the HG-induced inflammatory response in $\mathrm{H} 9 \mathrm{c} 2$ cardiac cells.
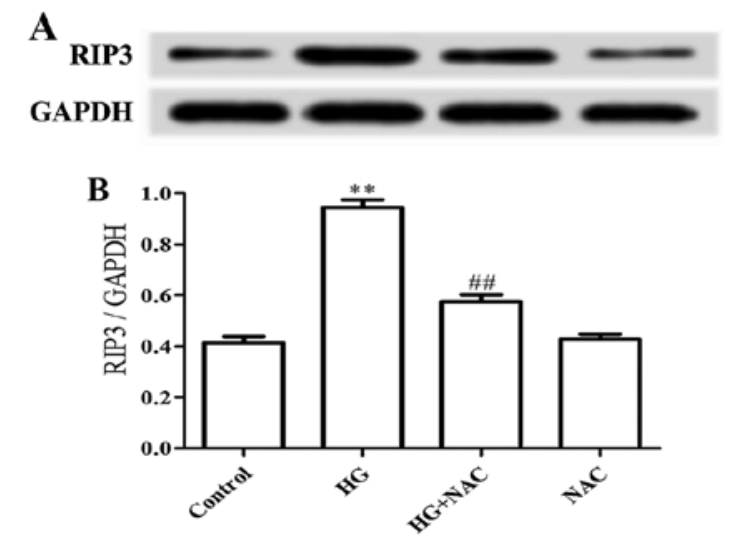

Figure 2. Reactive oxygen species (ROS) plays a role in the high glucose (HG)-induced increase in the expression level of receptor-interacting protein 3 (RIP3) in H9c2 cardiac cells. The protein expression level of RIP3 was semi-quantified by western blot analysis. (A) The cells were treated with or without $1 \mathrm{mM} \mathrm{N}$-acetyl-L-cysteine (NAC) (a scavenger of ROS) for $60 \mathrm{~min}$ prior to exposure to $35 \mathrm{mM}$ glucose (HG) for $24 \mathrm{~h}$. (B) Densitometric analysis of the expression level of RIP3 in (A). Data are shown as the means \pm SEM $(n=5)$ ${ }^{* *} \mathrm{P}<0.01$ vs. control group; ${ }^{\# \#} \mathrm{P}<0.01$ vs. the $\mathrm{HG}$-exposed group.
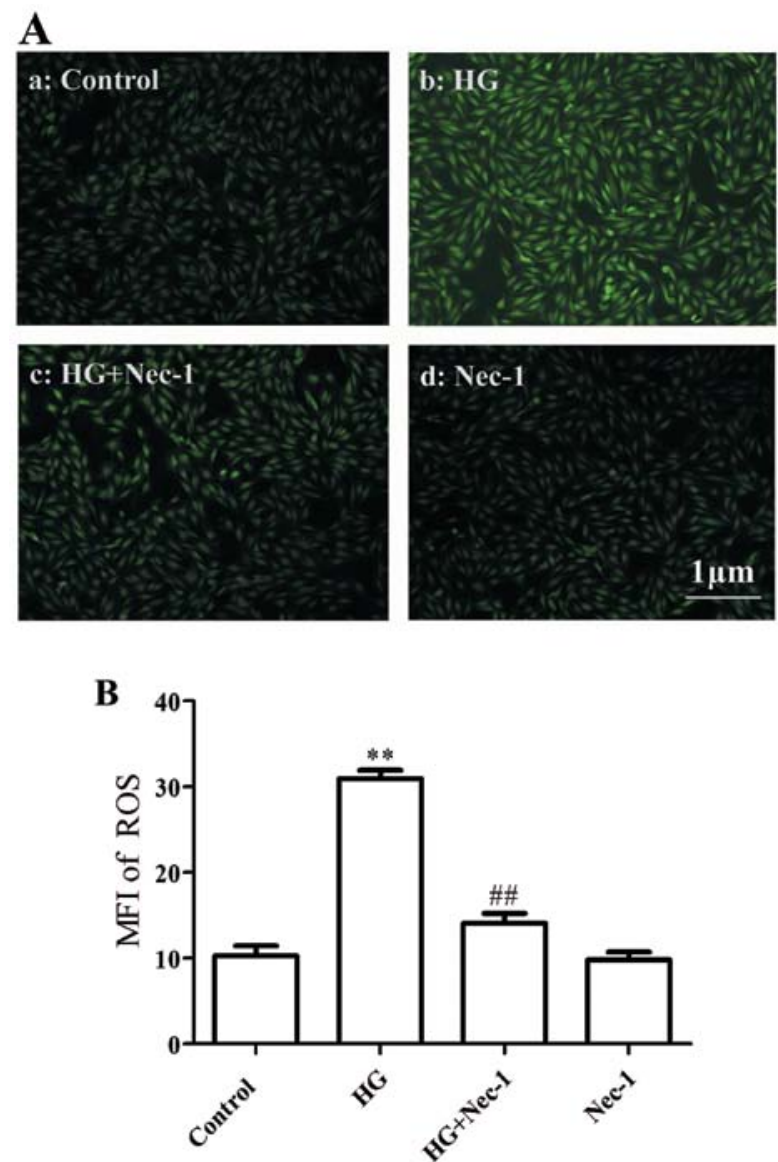

Figure 3. Necroptosis participates in high glucose (HG)-induced reactive oxygen species (ROS) generation in H9c2 cardiac cells. (A) After the cells were subjected to the indicated treatments, intracellular ROS generation was measured by $2^{\prime} 7^{\prime}$-dichlorodihydrofluoresein diacetate (DCFH-DA) staining followed by photofluorography. (A) Panel a, control group; panel b, H9c2 cardiac cells exposed to $35 \mathrm{mM}$ glucose (HG) for $24 \mathrm{~h}$; panel c, cells were co-treated with $100 \mu \mathrm{M}$ necrostatin-1 (Nec-1) and HG for $24 \mathrm{~h}$; panel d), cells were treated with $100 \mu \mathrm{M} \mathrm{Nec}-1$ for $24 \mathrm{~h}$. (B) Quantitive analysis of the mean fluorescence intensity (MFI) in panels a-d in (A) using ImageJ $1.47 \mathrm{i}$ software. Data are presented as the means \pm SEM $(n=5)$. ${ }^{* *} \mathrm{P}<0.01$ vs. control group; ${ }^{\# \#} \mathrm{P}<0.01$ vs. the HG-exposed group. 

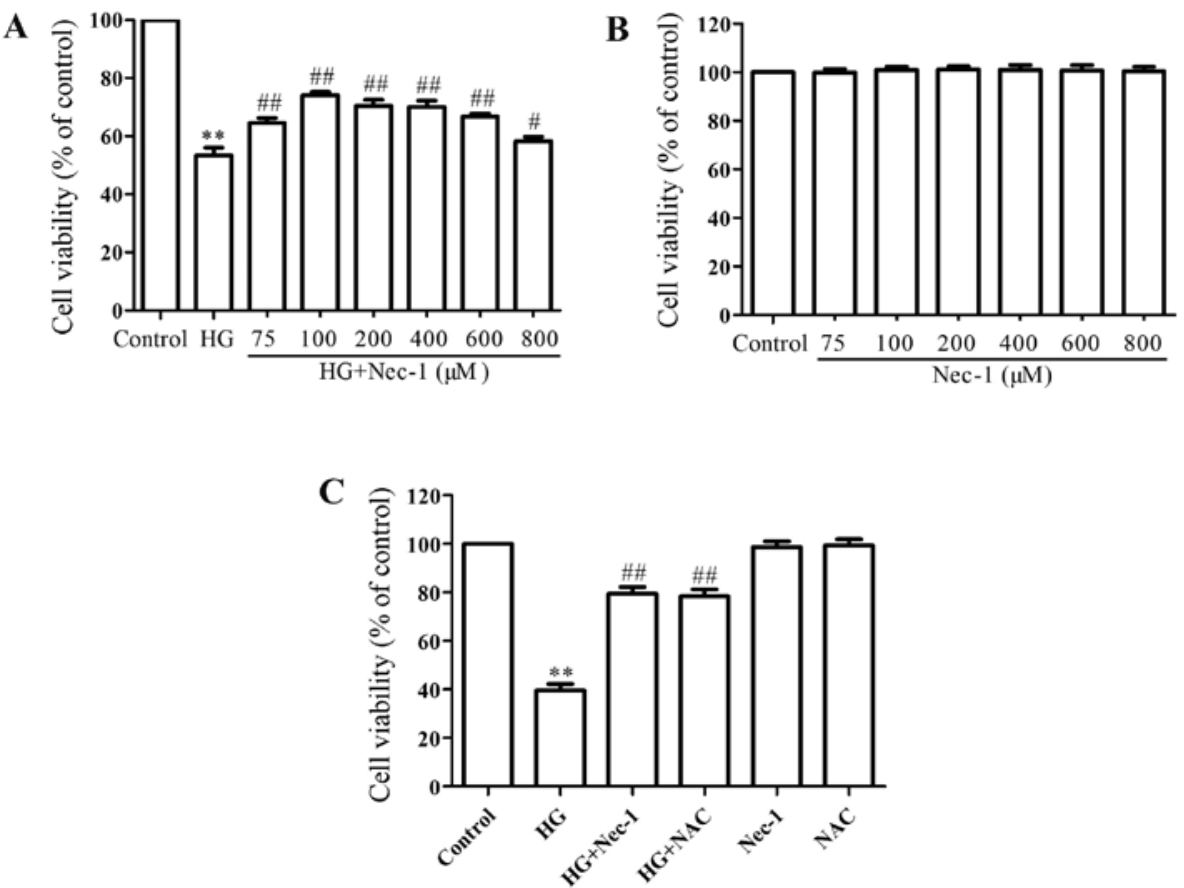

Figure 4. Necroptosis and reactive oxygen species (ROS) participate in high glucose (HG)-induced cytotoxicity to H9c2 cardiac cells. Cell viability was detected by Cell Counting Kit-8 (CCK-8) assay. (A) The cells were exposed to $35 \mathrm{mM}$ glucose (HG) for $24 \mathrm{~h}$ with or without 75, 100, 200, 400, 600 and 800 $\mu$ M necrostatin-1 (Nec-1). (B) The cells were incubated in the absence or presence of 75, 100, 200, 400, 600 and $800 \mu \mathrm{M} \mathrm{Nec-1.} \mathrm{(C)} \mathrm{The} \mathrm{cells} \mathrm{were} \mathrm{treated} \mathrm{with} \mathrm{HG} \mathrm{for}$ $24 \mathrm{~h}$ with or without co-treatment with $100 \mu \mathrm{M} \mathrm{Nec}-1$ or pre-treatment with $1 \mathrm{mM} \mathrm{NAC}$ for $60 \mathrm{~min}$. Data are presented as the means $\pm \mathrm{SEM}(\mathrm{n}=5)$. ${ }^{* *} \mathrm{P}<0.01$ vs. control group; ${ }^{\# \#} \mathrm{P}<0.01$ vs. the HG-exposed group; ${ }^{\#} \mathrm{P}<0.05$ vs. the HG-treated group.
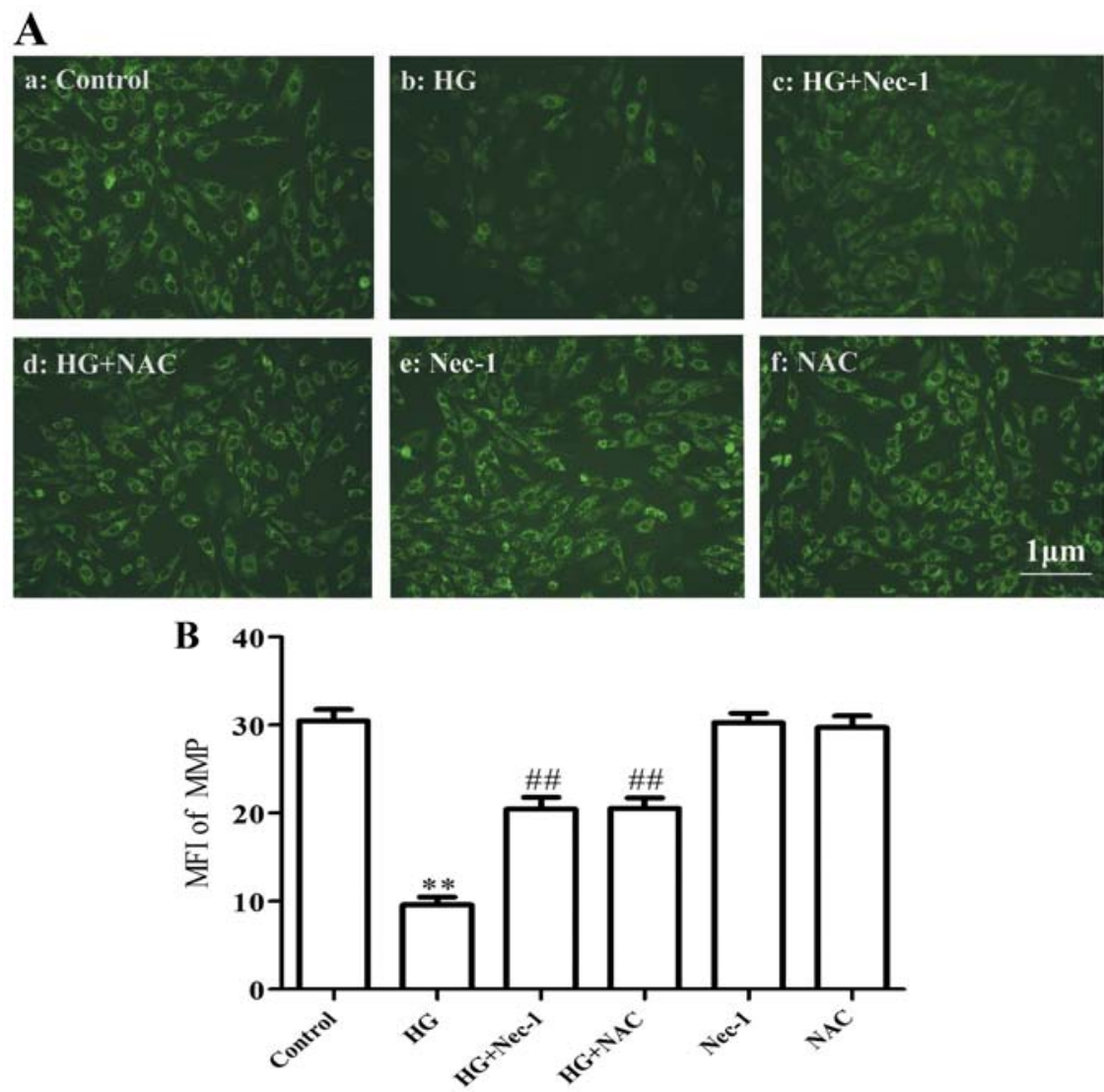

Figure 5. Necroptosis and reactive oxygen species (ROS) mediate the high glucose (HG)-induced dissipation of mitochondrial membrane potential (MMP) in H9c2 cardiac cells. (A) After the cells were subjected to the indicated treatments, MMP was examined by staining with the fluorescent dye, rhodamine 123 (Rh123), followed by photofluorography. (A) Panel a, control group; panel b, H9c2 cardiac cells exposed to $35 \mathrm{mM}$ glucose (HG) for $24 \mathrm{~h}$ or with (panel c) $100 \mu \mathrm{M}$ necrostatin-1 (Nec-1) and HG for $24 \mathrm{~h}$ or (panel d) $1 \mathrm{mM} \mathrm{N}$-acetyl-L-cysteine (NAC) for $60 \mathrm{~min}$ prior to exposure to HG for $24 \mathrm{~h}$; panel e), cells were treated with $100 \mu \mathrm{M} \mathrm{Nec}-1$ for $24 \mathrm{~h}$; panel f, cells were treated with $1 \mathrm{mM} \mathrm{NAC}$ for $60 \mathrm{~min}$. (B) Quantitative analysis of the mean fluorescence intensity (MFI) in panels a-f in (A) using ImageJ $1.47 \mathrm{i}$ software. Data are presented as the means $\pm \mathrm{SEM}(\mathrm{n}=5) .{ }^{* *} \mathrm{P}<0.01$ vs. control group; ${ }^{\# \#} \mathrm{P}<0.01$ vs. the HG-exposed group. 

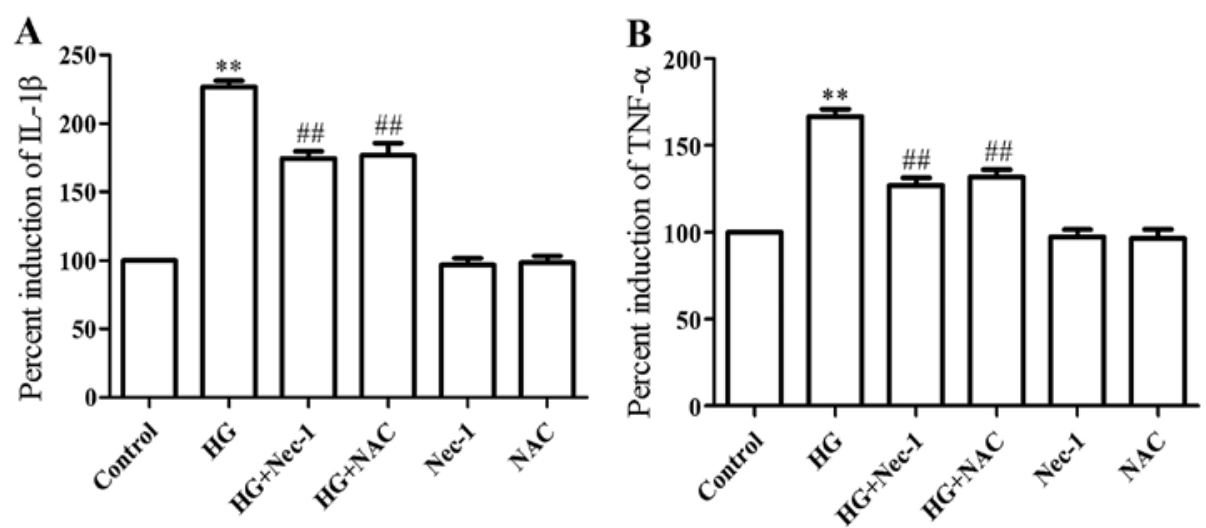

Figure 6. Necroptosis and reactive oxygen species (ROS) contribute to the high glucose (HG)-induced secretion of interleukin (IL)-1 $\beta$ and tumor necrosis factor- $\alpha$ (TNF- $\alpha$ ) in H9c2 cardiac cells. The cells were exposed to $35 \mathrm{mM}$ glucose for $24 \mathrm{~h}$ with or without co-treatment with $100 \mu \mathrm{M}$ necrostatin-1 (Nec-1) or pre-treatment with $1 \mathrm{mM} \mathrm{N}$-acetyl-L-cysteine (NAC) for $60 \mathrm{~min}$. Enzyme-linked immunosorbent assay (ELISA) was performed to determine the secretion levels of (A) IL-1 $\beta$ and (B) TNF- $\alpha$ in the cell supernatants. Data are presented as the means \pm SEM ( $n=5) .{ }^{* *} \mathrm{P}<0.01$ vs. control group; ${ }^{\# \#} \mathrm{P}<0.01$ vs. the HG-exposed group.

\section{Discussion}

To date, four forms of cell death have been defined and confirmed: necrosis, apoptosis, autophagy and necroptosis (35-37). Among these, apoptosis, necrosis and autophagy have been demonstrated to contribute to the development of DCM $(3,6,9,22,38,39)$. However, the role of necroptosis in hyperglycemia-induced cardiac injury remains incompletely understood, although Liu et al reported that the expression level of RIP3, a kinase promoting necroptosis, was upregulated in diabetic rats (22). In this study, to the best of our knowledge, we demonstrate for the first time that necroptosis plays important roles in HG-induced cardiac injury (cytotoxicity, oxidative stress and dissipation of MMP) and inflammation. Therefore, necroptosis may represent a promising novel target for therapeutic strategies in DCM. Moreover, the findings of this study suggested that there is a positive interaction between necroptosis and ROS production, which may be a novel mechanism underlying HG-elicited cardiac injury and inflammation.

Necroptosis (also known as programmed necrosis) represents a newly indentified mechanism of cell death combining the features of both apoptosis and necrosis. Several types of stimuli, including ligands of death receptors (such as Fas, TRAIL and TNF- $\alpha$ ), viral infection and anticancer agents, can induce necroptosis (40). In recent years, necroptosis has been demonstrated to be an important mediator of cell death in the heart (14,23-26). Several studies have indicated that I/R induces an increase in the expression levels of cardiac RIP1 and RIP3, and that Nec-1, an inhibitor of necroptosis, leads to a reduction in myocardial infarct size (23-25). Therefore, necroptosis may be a novel mechanism responsible for cardiac lesions. Recently, the effect of hyperglycemia on necroptosis has attracted attention. A more recent study by Liu et al demonstrated that RIP3 expression was enhanced in diabetic rats; however, the roles of necroptosis in hyperglycemia-induced cardiac injury were not determined (22).

In order to clarify this issue, in this study, we first observed the effects of HG on the expression level of RIP3 in cardiomyocytes. Consistent with the results reported by Liu et al (22), we found that the expression level of RIP3 was upregulated in
HG-exposed H9c2 cardiac cells. Combining our results and the ones reported by Liu et al, it is suggested that hyperglycemia is a strong stimuli for inducing necroptosis. Second, we examined the effects of Nec-1 on HG-induced cardiac injury (including cytotoxicity, ROS generation and dissipation of MMP). The findings of the present study indicated that Nec-1 markedly attenuated the increased expression of RIP3 by HG, along with the inhibitory effects on HG-induced cardiac injury, as evidenced by an increase in cell viability, a decrease in ROS generation and the attenuation of the dissipation of MMP. These results provide novel evidence that necroptosis contributes to HG-induced cardiomyocyte injury, and extend the findings reported by Liu et al (22).

Another important result of this study relates to the role of necroptosis in HG-induced cardiomyocyte inflammation. Chronic mild inflammation has been considered as one of the features of DCM in humans $(41,42)$. Moreover, in a mouse model of streptozotocin-induced type 1 diabetes, anti-inflammatory therapy represented a potential approach for the therapy of diabetes and its complications (43). Therefore, the further exploration of the mechanisms and the identification of novel therapeutic targets of HG-induced inflammatory response has a promising future. Inflammatory signaling molecules, such as TNF- $\alpha$, Fas and TRAIL, have been reported to be initiators of necroptosis $(40,44)$. On the other hand, necroptosis has been found to trigger intestinal inflammation, acute pancreatitis, experimental sepsis, salmonella infection and inflammation in atherosclerosis $(45,46)$. Our results demonstrated that the exposure of H9c2 cardiac cells to HG induced an obvious inflammatory response, as evidenced by the increased secretion levels of IL-1 $\beta$ and TNF- $\alpha$, whichwasis similar to the results of our previous study (13). However, the increased secretion of IL- $1 \beta$ and TNF- $\alpha$ was ameliorated by Nec-1, indicating the involvement of necroptosis in HG-induced inflammation. Of note, necroptosis was triggered by TNF- $\alpha$ (40), and we demonstrated the contribution of necroptosis to the HG-induced increase in TNF- $\alpha$ secretion; thus, we speculated that there was a positive feedback loop between necroptosis and TNF- $\alpha$ in the HG-treated H9c2 cardiac cells. To confirm this hypothesis, further studies are required. 
Importantly, it has been shown that there is a positive interaction between necroptosis and ROS generation in BV6/TNF- $\alpha$-treated Jurkat cells (34). This led us to explore whether there was a similar interaction between necroptosis and ROS generation in HG-exposed cardiac cells. Our results demonstrated that NAC, a ROS scavenger, markedly ameliorated the HG-induced an increase in RIP3 expression, accompanied by the inhibition of the HG-induced cardiac injury and inflammation, as indicated by an increase in cell viability and a decrease in ROS generation, the attenuation of MMP dissipation and a derease in the secretion levels of IL-1 $\beta$ and TNF- $\alpha$ induced by HG. These results clearly demonstrate that a positive feedback loop between necroptosis and ROS production exists in HG-exposed $\mathrm{H} 9 \mathrm{c} 2$ cardiac cells, which plays important roles in cardiac injury and inflammation induced by HG. Since the roles of necroptosis and ROS in diabetic cardiac injury have been emphasized by us and others, further experiments using conditional RIP3-knockout mice are warranted in order to clarify the mutual interaction between necroptosis and ROS generation in vivo.

In conclusion, revealing the contribution of necroptosis to HG-induced cardiac injury and inflammation, the present study provides further insight into the mechanisms underlying diabetic cardiovascular complications, such as DCM. Considering the significance of the positive interaction between necroptosis and ROS generation in HG-induced cardiac injury and inflammation, a better understanding of the molecular mechanisms of this interaction will likely have important implications for the development of novel strategies to interfere with necroptosis and ROS generation in patients with diabetes.

\section{Acknowledgements}

The present study was supported by grants from Guangdong Natural Science Foundation (no. 2015A030313690).

\section{References}

1. Brownlee M: Biochemistry and molecular cell biology of diabetic complications. Nature 414: 813-820, 2001.

2. Ren J and Davidoff AJ: Diabetes rapidly induces contractile dysfunctions in isolated ventricular myocytes. Am J Physiol 272: H148-H158, 1997.

3. Xu W, Wu W, Chen J, Guo R, Lin J, Liao X and Feng J: Exogenous hydrogen sulfide protects $\mathrm{H} 9 \mathrm{c} 2$ cardiac cells against high glucose-induced injury by inhibiting the activities of the p38 MAPK and ERK1/2 pathways. Int J Mol Med 32: 917-925, 2013.

4. Soetikno V, Sari FR, Sukumaran V, Lakshmanan AP, Mito S, Harima M, Thandavarayan RA, Suzuki K, Nagata M, Takagi $\mathrm{R}$, et al: Curcumin prevents diabetic cardiomyopathy in streptozotocin-induced diabetic rats: possible involvement of PKC-MAPK signaling pathway. Eur J Pharm Sci 47: 604-614, 2012

5. Peake BF, Nicholson CK, Lambert JP, Hood RL, Amin H, Amin S and Calvert JW: Hydrogen sulfide preconditions the $d b / d b$ diabetic mouse heart against ischemia-reperfusion injury by activating Nrf2 signaling in an Erk-dependent manner. Am J Physiol Heart Circ Physiol 304: H1215-H1224, 2013.

6. Chen J, Mo H, Guo R, You Q, Huang R and Wu K: Inhibition of the leptin-induced activation of the p38 MAPK pathway contributes to the protective effects of naringin against high glucose-induced injury in H9c2 cardiac cells. Int J Mol Med 33: 605-612, 2014

7. Huang H, Wu K, You Q, Huang R, Li S and Wu K: Naringin inhibits high glucose-induced cardiomyocyte apoptosis by attenuating mitochondrial dysfunction and modulating the activation of the p38 signaling pathway. Int J Mol Med 32: 396-402, 2013.
8. Cai L, Li W, Wang G, Guo L, Jiang Y and Kang YJ: Hyperglycemia-induced apoptosis in mouse myocardium: mitochondrial cytochrome $C$-mediated caspase-3 activation pathway. Diabetes 51: 1938-1948, 2002.

9. Chen J, Guo R, Yan H, Tian L, You Q, Li S, Huang R and Wu K: Naringin inhibits ROS-activated MAPK pathway in high glucose-induced injuries in $\mathrm{H} 9 \mathrm{c} 2$ cardiac cells. Basic Clin Pharmacol Toxicol 114: 293-304, 2014.

10. Fiordaliso F, Leri A, Cesselli D, Limana F, Safai B, Nadal-Ginard B, Anversa P and Kajstura J: Hyperglycemia activates p53 and p53-regulated genes leading to myocyte cell death. Diabetes 50: 2363-2375, 2001.

11. Fei L, Yong-Jun H, Zhang-Min M, Bing X, Shuang W, Qian-qian S and Jun L: Rosiglitazone attenuates memory impairment in aged rat with diabetes by inhibiting NF-kappa B signal pathway activation. Exp Clin Endocrinol Diabetes 123: 536-542, 2015.

12. Thandavarayan RA, Giridharan VV, Sari FR, Arumugam S, Veeraveedu PT, Pandian GN, Palaniyandi SS, Ma M, Suzuki K, Gurusamy N, et al: Depletion of 14-3-3 protein exacerbates cardiac oxidative stress, inflammation and remodeling process via modulation of MAPK/NF- $\kappa$ B signaling pathways after streptozotocin-induced diabetes mellitus. Cell Physiol Biochem 28: 911-922, 2011.

13. Xu W, Chen J, Lin J, Liu D, Mo L, Pan W, Feng J, Wu W and Zheng D: Exogenous $\mathrm{H}_{2} \mathrm{~S}$ protects $\mathrm{H} 9 \mathrm{c} 2$ cardiac cells against high glucose-induced injury and inflammation by inhibiting the activation of the NF- $\mathrm{NB}$ and IL-1 $\beta$ pathways. Int J Mol Med 35: 177-186, 2015.

14. Kung G, Konstantinidis K and Kitsis RN: Programmed necrosis, not apoptosis, in the heart. Circ Res 108: 1017-1036, 2011

15. Declercq W, Vanden Berghe T and Vandenabeele P: RIP kinases at the crossroads of cell death and survival. Cell 138: 229-232, 2009.

16. Zhang DW, Shao J, Lin J, Zhang N, Lu BJ, Lin SC, Dong MQ and Han J: RIP3, an energy metabolism regulator that switches TNF-induced cell death from apoptosis to necrosis. Science 325: 332-336, 2009.

17. He S, Wang L, Miao L, Wang T, Du F, Zhao L and Wang X: Receptor interacting protein kinase-3 determines cellular necrotic response to TNF-alpha. Cell 137: 1100-1111, 2009.

18. Cho YS, Challa S, Moquin D, Genga R, Ray TD, Guildford M and Chan FK: Phosphorylation-driven assembly of the RIP1-RIP3 complex regulates programmed necrosis and virus-induced inflammation. Cell 137: 1112-1123, 2009.

19. Linkermann A, Hackl MJ, Kunzendorf U, Walczak H, Krautwald S and Jevnikar AM: Necroptosis in immunity and ischemia-reperfusion injury. Am J Transplant 13: 2797-2804, 2013.

20. Dmitriev YV,Minasian SM, Demchenko EA and Galagudza MM: Study of cardioprotective effects of necroptosis inhibitors on isolated rat heart subjected to global ischemia-reperfusion. Bull Exp Biol Med 155: 245-248, 2013.

21. Koshinuma S, Miyamae M, Kaneda K, Kotani J and Figueredo VM: Combination of necroptosis and apoptosis inhibition enhances cardioprotection against myocardial ischemia-reperfusion injury. J Anesth 28: 235-241, 2014.

22. Liu YS, Huang ZW, Wang L, Liu XX, Wang YM, Zhang Y and Zhang M: Sitagliptin alleviated myocardial remodeling of the left ventricle and improved cardiac diastolic dysfunction in diabetic rats. J Pharmacol Sci 127: 260-274, 2015.

23. Oerlemans MI, Liu J, Arslan F, den Ouden K, van Middelaar BJ, Doevendans PA and Sluijter JP: Inhibition of RIP1-dependent necrosis prevents adverse cardiac remodeling after myocardial ischemia-reperfusion in vivo. Basic Res Cardiol 107: 270, 2012.

24. Lim SY, Davidson SM, Mocanu MM, Yellon DM and Smith CC: The cardioprotective effect of necrostatin requires the cyclophilin-D component of the mitochondrial permeability transition pore. Cardiovasc Drugs Ther 21: 467-469, 2007.

25. Smith CC, Davidson SM, Lim SY, Simpkin JC, Hothersall JS and Yellon DM: Necrostatin: a potentially novel cardioprotective agent? Cardiovasc Drugs Ther 21: 227-233, 2007.

26. Luedde M, Lutz M, Carter N, Sosna J, Jacoby C, Vucur M, Gautheron J, Roderburg C, Borg N, Reisinger F, et al: RIP3, a kinase promoting necroptotic cell death, mediates adverse remodelling after myocardial infarction. Cardiovasc Res 103: 206-216, 2014.

27. Meng L, Jin W and Wang X: RIP3-mediated necrotic cell death accelerates systematic inflammation and mortality. Proc Natl Acad Sci USA 112: 11007-11012, 2015. 
28. Han D, Ybanez MD, Ahmadi S, Yeh K and Kaplowitz N: Redox regulation of tumor necrosis factor signaling. Antioxid Redox Signal 11: 2245-2263, 2009.

29. Morgan MJ and Liu ZG: Reactive oxygen species in TNFalpha-induced signaling and cell death. Mol Cells 30: $1-12,2010$.

30. Fortes GB, Alves LS, de Oliveira R, Dutra FF, Rodrigues D, Fernandez PL, Souto-Padron T, De Rosa MJ, Kelliher M, Golenbock D, et al: Heme induces programmed necrosis on macrophages through autocrine TNF and ROS production. Blood 119: 2368-2375, 2012.

31. Ye YC, Wang HJ, Yu L, Tashiro S, Onodera S and Ikejima T: RIP1-mediated mitochondrial dysfunction and ROS production contributed to tumor necrosis factor alpha-induced L929 cell necroptosis and autophagy. Int Immunopharmacol 14 674-682, 2012.

32. Yu X, Deng Q, Li W, Xiao L, Luo X, Liu X, Yang L, Peng S, Ding Z, Feng T, et al: Neoalbaconol induces cell death through necroptosis by regulating RIPK-dependent autocrine TNF $\alpha$ and ROS production. Oncotarget 6: 1995-2008, 2015.

33. Kikuchi M, Kuroki S, Kayama M, Sakaguchi S, Lee KK and Yonehara S: Protease activity of procaspase- 8 is essential for cell survival by inhibiting both apoptotic and nonapoptotic cell death dependent on receptor-interacting protein kinase 1 (RIP1) and RIP3. J Biol Chem 287: 41165-41173, 2012.

34. Schenk B and Fulda S: Reactive oxygen species regulate Smac mimetic/TNF $\alpha$-induced necroptotic signaling and cell death. Oncogene 34: 5796-5806, 2015.

35. Nunes T, Bernardazzi C and de Souza HS: Cell death and inflammatory bowel diseases: apoptosis, necrosis, and autophagy in the intestinal epithelium. BioMed Res Int 2014: 218493, 2014

36. Fenton K: The effect of cell death in the initiation of lupus nephritis. Clin Exp Immunol 179: 11-16, 2015.

37. Su Z, Yang Z, Xu Y, Chen Y and Yu Q: Apoptosis, autophagy, necroptosis, and cancer metastasis. Mol Cancer 14: 48, 2015.
38. Fang ZY, Prins JB and Marwick TH: Diabetic cardiomyopathy: evidence, mechanisms, and therapeutic implications. Endocr Rev 25: 543-567, 2004.

39. Shimomura H, Terasaki F, Hayashi T, Kitaura Y, Isomura T and Suma H: Autophagic degeneration as a possible mechanism of myocardial cell death in dilated cardiomyopathy. Jpn Circ J 65: 965-968, 2001.

40. Vanlangenakker N, Vanden Berghe $\mathrm{T}$ and Vandenabeele $\mathrm{P}$ : Many stimuli pull the necrotic trigger, an overview. Cell Death Differ 19: 75-86, 2012.

41. Boudina S, Sena S, Theobald H, Sheng X, Wright JJ, Hu XX, Aziz S, Johnson JI, Bugger H, Zaha VG, et al: Mitochondrial energetics in the heart in obesity-related diabetes: direct evidence for increased uncoupled respiration and activation of uncoupling proteins. Diabetes 56: 2457-2466, 2007.

42. Agrawal NK and Kant S: Targeting inflammation in diabetes: newer therapeutic options. World J Diabetes 5: 697-710, 2014

43. Fang Q, Wang J, Wang L, Zhang Y, Yin H, Li Y, Tong C, Liang G and Zheng $\mathrm{C}$ : Attenuation of inflammatory response by a novel chalcone protects kidney and heart from hyperglycemia-induced injuries in type 1 diabetic mice. Toxicol Appl Pharmacol 288: 179-191, 2015.

44. Yu X, Deng Q, Bode AM, Dong Z and Cao Y: The role of necroptosis, an alternative form of cell death, in cancer therapy. Expert Rev Anticancer Ther 13: 883-893, 2013.

45. Yang Y, Jiang G, Zhang P and Fan J: Programmed cell death and its role in inflammation. Mil Med Res 2: 12, 2015.

46. Liu ZY, Wu B, Guo YS, Zhou YH, Fu ZG, Xu BQ, Li JH, Jing L, Jiang JL, Tang J, et al: Necrostatin-1 reduces intestinal inflammation and colitis-associated tumorigenesis in mice. Am J Cancer Res 5: 3174-3185, 2015. 